\title{
Oxygen-rich Hierarchical Porous Carbon Derived from Coal Tar Pitch for Superior Electric Double Layer Capacitor Application
}

Qi-Qi Zhuang, Jing-Pei Cao*, Zhi-Qiang Hao, Xiao Wan, Yan Wu, Zhong-Hai Ni, Xiao-Yan Zhao**, Xian-Yong Wei

Key Laboratory of Coal Processing and Efficient Utilization (Ministry of Education), China University of Mining \& Technology, Xuzhou 221116, Jiangsu, China

*E-mail: caojingpei@cumt.edu.cn

${ }^{* *}$ E-mail: zhaoxiaoyan@cumt.edu.cn

doi: $10.20964 / 2018.09 .33$

Received: 15 May 2018 / Accepted: 28 June 2018 / Published: 5 August 2018

Coal tar pitch (CTP) with a great deal of polynuclear aromatic structural units is a potential precursor for preparing porous carbon. In this paper, CTP was selected as raw material, and oxygen-rich hierarchical porous carbon (OHPC) was prepared successfully by facile one-step KOH activation, which was attributed to the $\mathrm{H}_{2} \mathrm{O}$ oxidation during this process. The oxygen content in hierarchical porous carbon was well above the oxygen content in CTP. Besides, possible oxidation mechanism was proposed. The influence of activation temperature and activation ratio $\left(m_{\mathrm{KOH}} / m_{\mathrm{CTP}}\right)$ on the pore structure of OHPC was also investigated, and the largest specific surface area reached $2342 \mathrm{~m}^{2} \mathrm{~g}^{-1}$. When OHPC was applied to electric double layer capacitor in the two electrode system, it shows good electrochemical performance. Its specific capacitance and energy density could reach $308 \mathrm{~F} \mathrm{~g}^{-1}$ and $8.31 \mathrm{Wh} \mathrm{kg}^{-1}$ in $6 \mathrm{M} \mathrm{KOH}$ solution, respectively. Meanwhile, the capacitance retention of OHPCs was up to $95.4 \%$ at $2 \mathrm{~A} \mathrm{~g}^{-1}$ after 10000 cycles. This paper not only provides a simple method of oxygen doping for porous carbon, but also achieve the green and high value-added utilization of CTP.

Keywords: Coal tar pitch; Oxygen-rich hierarchical porous carbon; Steam oxidation; Electric double layer capacitor

\section{$\underline{\text { FULL TEXT }}$}

(C) 2018 The Authors. Published by ESG (www.electrochemsci.org). This article is an open access article distributed under the terms and conditions of the Creative Commons Attribution license (http://creativecommons.org/licenses/by/4.0/). 